\title{
Total Clearance Predicted Normalized by
} Surface Area

National Cancer Institute

\section{Source}

National Cancer Institute. Total Clearance Predicted Normalized by Surface Area. NCI

Thesaurus. Code C92423.

The predicted total body clearance for intravascular administration divided by the surface area. 